\section{"Tem mulher, tem preventivo": sentidos das práticas preventivas do câncer do colo do útero entre mulheres de Salvador, Bahia, Brasil}

\author{
"Where there's a woman, there's a Pap smear": the \\ meanings assigned to cervical cancer prevention \\ among women in Salvador, \\ Bahia State, Brazil
"Hay mujer, hay Papanicolaou": sentidos de las prácticas preventivas del cáncer de cuello de útero \\ entre mujeres de Salvador, Bahía, Brasil
}

Ana María Rico 1

Jorge Alberto Bernstein Iriart 1

\author{
${ }_{1}$ Instituto de Saúde Coletiva \\ Universidade Federal da \\ Bahia, Salvador, Brasil. \\ Correspondência \\ A. M. Rico \\ Instituto de Saúde Coletiva \\ Universidade Federal da \\ Bahia. \\ Rua Basílio da Gama s/n, \\ Campus Universitário Canela \\ Salvador, BA 40110-060, \\ Brasil. \\ ricoanam@gmail.com
}

\begin{abstract}
This study focuses on the meanings assigned to practices for cervical cancer prevention among women from low-income neighborhoods in Salvador, Bahia State, Brazil. This was a qualitative study based on content analysis of semi-structured interviews with 15 women 24 to 68 years of age. The results showed high appreciation of the Pap smear test, performed as part of routine gynecological examination (but without the patient necessarily having biomedical knowledge of its role). Besides accessibility and quality of health services, other factors influence the way the women assign meaning to cervical cancer prevention. Moral values associated with sexuality and gender influence risk perception, adoption of preventive practices, and interpretation of cervical cytology results. The ongoing practice of the Pap smear test is part of the construction of femininity, which is associated with maturity and personal responsibility for self care in a context of medicalization of the female body.
\end{abstract}

Cervix Neoplasms Prevention; Gender Identity; Sexuality

\section{Resumo}

O objetivo deste trabalho foi compreender os significados das práticas preventivas do câncer do colo do útero entre mulheres de bairros populares de Salvador, Bahia, Brasil. Trata-se de estudo qualitativo, baseado na análise de conteúdo de entrevistas semiestruturadas com 15 mulheres entre 24 e 68 anos. Os resultados evidenciam alta valorização do Papanicolaou, que é realizado como parte de exames de rotina, sem, no entanto, sustentar-se no conhecimento biomédico sobre as suas funções. Além da acessibilidade aos serviços de saúde e da qualidade destes, outros fatores interferem na forma como essas mulheres significam a prevenção do câncer do colo do útero. Valores morais associados à sexualidade e ao gênero interferem na percepção de risco, na adoção de práticas preventivas e na interpretação dos resultados da citologia cervical. A realização continuada do Papanicolaou faz parte da construção da feminilidade, que é associada com maturidade e responsabilidade pessoal pelo cuidado de si em um contexto de medicalização do corpo feminino.

Prevenção de Câncer de Colo Uterino; Identidade de Gênero; Sexualidade 


\section{Introdução}

Apesar de se tratar de uma doença evitável e tratável, o câncer do colo do útero é um importante problema de saúde pública. Trata-se do terceiro tumor mais frequente entre as mulheres no mundo, $80 \%$ dos casos ocorrendo em países em desenvolvimento ${ }^{1}$.

No Brasil, é o segundo tumor mais diagnosticado em mulheres 2 , tendo sido esperados 17.540 casos novos em 2012 e um risco estimado de 17 casos a cada 100 mil mulheres 3 . Verificam-se diferenças na carga da doença, no interior do país. Em 2009, as taxas de mortalidade específicas ajustadas pela população mundial variaram entre um e 15 óbitos por cada 100 mil mulheres 4 . O câncer do colo do útero afeta as mulheres de menor nível socioeconômico e com dificuldades de acesso aos serviços de saúde 5 , traçando perfis de morbimortalidade evitáveis e injustos, que refletem a iniquidade em saúde. A incidência, no Brasil, evidencia-se a partir dos 20-29 anos, e o maior risco encontra-se na faixa etária de 4549 anos. Entretanto, a mortalidade resulta mais significativa à medida que aumenta a idade em virtude do prolongado período que compreende a transmissão sexual do HPV, o adoecimento e a morte por câncer do colo do útero (Departamento de Informática do SUS. Sistema de Informações sobre Mortalidade. http://www2.datasus. gov.br/DATASUS/index.php?area=0205, acessado em Set/2011). Por sua magnitude, constitui o foco das políticas públicas de controle do câncer, sendo o único tumor incluído no Pacto pela Vida, junto com o de mama 6 .

Com exceção do câncer de pele, o câncer cervical é o que apresenta maior potencial de prevenção e cura quando diagnosticado precocemente. Uma redução de $80 \%$ da mortalidade pode ser alcançada por meio do rastreamento para a detecção da doença entre mulheres assintomáticas, na faixa etária de 25-65 anos, mediante o exame de Papanicolaou e o tratamento das lesões com potencial de malignidade ou carcinoma in situ. No Brasil, essa estratégia é recomendada pelo Ministério da Saúde para mulheres entre 25 e 59 anos 7 . Avaliações recentes 8 destacam importantes melhoras na cobertura do exame, porém assinalam que o acesso continua sendo problemático nas áreas mais pobres, com taxas de mortalidade ascendentes em zonas rurais do Norte e Nordeste, contrastando com a tendência nacional decrescente.

Estudos realizados em países em desenvolvimento apontam diversos fatores que interferem nas práticas preventivas das mulheres, como seus conhecimentos e representações sobre a doença e sobre o Papanicolaou, a acessibilidade e a qualidade dos serviços de saúde, as práticas de cuidado da saúde sexual, as atitudes dos parceiros, o medo da dor e os pudores relacionados à exposição do corpo, dentre outros 9,10,11,12. Evidencia-se, assim, que, além da dimensão técnica do problema, as políticas preventivas devem contemplar sua dimensão simbólica, considerando a interação entre a informação fornecida pelos programas, as ações dos serviços e as concepções e práticas da população.

A prevenção do câncer do colo do útero requer problematizar, também, a interação entre gênero, cuidado com a saúde e medicalização dos corpos femininos. O conceito de gênero diz respeito às relações socialmente construídas entre homens e mulheres e à assimetria de poder que permeia tais relações 13. De caráter performativo, o gênero é produzido por atos reiterados, cuja cristalização no tempo lhe confere uma aparência substantiva 14. Já por medicalização, entendemos o processo mediante o qual dimensões da vida, experiências e problemas originalmente fora da alçada médica passam a ser definidos e tratados como problemas médi$\cos 15$. Por sua vez, o corpo feminino constituiuse, historicamente, em um objeto privilegiado de intervenção da biomedicina, com ênfase no controle da saúde sexual e reprodutiva. Articulando essas categorias analíticas, consideramos, como Courtenay 16, que as crenças e práticas em saúde também constituem formas de construir representações de gênero.

Com base nessas premissas, este estudo teve por objetivo compreender os significados e as práticas associados ao câncer do colo do útero e ao Papanicolaou por mulheres de camadas populares da cidade de Salvador, com especial atenção aos discursos relativos ao gênero e à sexualidade, os quais permeiam essas dimensões no contexto da medicalização do corpo feminino.

\section{Metodologia}

Adotou-se uma perspectiva qualitativa, visando conhecer em profundidade as significações e práticas de mulheres de bairros populares de Salvador em relação ao câncer de colo do útero e sua prevenção.

A pesquisa foi realizada no Distrito Sanitário da Liberdade, cuja população é predominantemente negra e de baixa renda (Secretaria de Saúde do Estado da Bahia. http://www.tabnet. saude.salvador.ba.gov.br/deftohtm.exe?tabpop/ populacao.def, acessado em Fev/2012). O Distrito Sanitário da Liberdade conta com várias unidades assistenciais, incluídas cinco instituições da atenção básica. 
O trabalho de campo foi realizado entre agosto e dezembro de 2011, durante o qual 15 mulheres foram entrevistadas em profundidade. Os critérios de inclusão no estudo foram os seguintes: ser mulher maior de 18 anos e residir no Distrito Sanitário da Liberdade. As cinco primeiras informantes foram contatadas a partir de incursões ao Distrito Sanitário da Liberdade, ocasião em que a pesquisadora acompanhou visitas domiciliares de agentes comunitários de saúde. Considerando, no entanto, que a falta de acesso aos serviços de saúde é tida como cofator de risco para o desenvolvimento da doença, procurou-se selecionar mulheres sem vínculos diretos com os serviços, presumindo-se que elas formariam parte de grupos mais vulneráveis. Assim, seis participantes foram localizadas por intermédio de uma instituição de assistência social, enquanto as restantes foram contatadas por meio de uma associação de moradores.

A seleção das informantes tentou contemplar a máxima heterogeneidade possível conforme as seguintes categorias de interesse: situação conjugal, idade, renda familiar, religião e nível de instrução. Procurou-se identificar mulheres que nunca tivessem realizado um Papanicolaou, que pertenceriam a um grupo mais vulnerável à enfermidade; no entanto, apesar das diversas estratégias de identificação das participantes da pesquisa, todas as mulheres contatadas declararam ter realizado o exame pelo menos uma vez na vida.

Utilizou-se a entrevista semiestruturada como técnica de produção de dados, complementada pelo registro de entrevistas informais e observações em diário de campo. Foi elaborado um roteiro de entrevista que abordou os seguintes temas: cuidado de si e da família, cuidados da saúde sexual, significados do câncer do colo do útero e do Papanicolaou, práticas de cuidado e relações de gênero. As entrevistas, com duração média de uma hora, foram gravadas e posteriormente transcritas. Todos os encontros ocorreram nos domicílios das mulheres, à exceção de um, realizado em uma instituição local. A seguir, apresentam-se as informantes conforme as principais características de interesse (Tabela 1).

Cabe salientar que seis participantes recebem benefícios sociais, três das quais estão inscritas no Programa Bolsa Família e outras três estão aposentadas. As atividades econômicas desenvolvidas são de tipo informal, exceto para uma entrevistada, que trabalha na área da saúde. Duas informantes são atendentes de bares, duas são empregadas domésticas e outras duas fornecem serviços cosméticos. Duas aposentadas provedoras do lar complementam sua renda vendendo alimentos elaborados por elas, a entre- vistada mais nova está procurando emprego e as restantes são donas de casa.

Para a análise dos dados produzidos, adotou-se a técnica de análise de conteúdo temática, visando a detectar unidades de sentido que permitissem compreender significados de natureza sociológica e cultural 17. Partiu-se do pressuposto de que os significados e práticas associados ao corpo, à saúde e à doença são construídos a partir de universos socioculturais específicos 18. Concebe-se o discurso médico como um sistema cultural, cujas idéias, valores e práticas perpassam a cultura popular 19, ao mesmo tempo em que são passíveis de serem contestados, apropriados e reinterpretados pelos sujeitos 20 .

Partindo da leitura reiterada das transcrições, alternou-se leitura flutuante e focalizada, na busca de padrões reiterados e contradições, à luz do marco teórico e das presunções subjacentes à pesquisa. Para orientar a análise, elaborou-se

Tabela 1

Caracterização das informantes.

\begin{tabular}{|c|c|}
\hline Variáveis & $\mathbf{n}$ \\
\hline \multicolumn{2}{|l|}{ Idade (anos) } \\
\hline $24-35$ & 4 \\
\hline $36-55$ & 7 \\
\hline $56-68$ & 4 \\
\hline \multicolumn{2}{|l|}{ Situação conjugal } \\
\hline Com parceiro & 8 \\
\hline Sem parceiro (solteira, separada ou viúva) & 7 \\
\hline \multicolumn{2}{|l|}{ Número de integrantes do lar } \\
\hline 1 & 1 \\
\hline Até 3 & 9 \\
\hline Até 8 & 5 \\
\hline \multicolumn{2}{|l|}{ Nível educacional } \\
\hline Ensino Fundamental & 6 \\
\hline Ensino Médio & 5 \\
\hline Ensino Superior & 4 \\
\hline \multicolumn{2}{|l|}{ Provedora principal do lar } \\
\hline Sim & 6 \\
\hline Não & 9 \\
\hline \multicolumn{2}{|l|}{ Rendimento mensal do lar (salário mínimo) } \\
\hline Até 1 & 5 \\
\hline Até 2 & 6 \\
\hline Até 3 & 4 \\
\hline \multicolumn{2}{|l|}{ Percebe benefício social } \\
\hline Sim & 6 \\
\hline Não & 9 \\
\hline
\end{tabular}


uma matriz de dados com base nas dimensões de interesse. Para organizar o material, utilizou-se o programa informático de processamento de dados não estruturados QRS NVivo versão 2.0.161 (QRS International Pty, Doncaster, Austrália).

O projeto foi aprovado pelo Comitê de Ética em Pesquisa do Instituto de Saúde Coletiva, Universidade Federal da Bahia (no 021-11 CEP/ISC), pela Secretaria Municipal da Saúde de Salvador e pelo DSL. Os nomes das participantes são fictícios a fim de garantir seu anonimato.

\section{Resultados e discussão}

"Tem mulher, tem preventivo": Papanicolaou e feminilidade

Grande parte da literatura sobre as barreiras para o rastreamento do câncer do colo do útero privilegia a relação entre informação sobre o Papanicolaou e sua realização 11,12 . Outras pesquisas, apesar de relativizarem essa associação, mostrando que a ciência sobre o exame não implica sua realização automática 5,10,21, continuam, porém, conferindo-lhe centralidade. Neste estudo, a valorização do Papanicolaou e a sua prática não parecem derivar necessariamente dessa informação, mas de critérios de outra índole.

Segundo as entrevistadas, o Papanicolaou teria diversas funções e graus de especificidade. Para algumas, ele permite conferir o estado de saúde das "partes femininas", prevenir ou detectar DSTs e outros problemas em diferentes partes do aparato reprodutor feminino:

"Por exemplo, se você tiver com início de qualquer... doença ou qualquer coisa, o preventivo ele lhe acusa. Se você tiver... como é que diz, um tumor, você pode ver se ele é benigno, se é maligno... Se você tiver... outro tipo de doença no seu útero ou... ou na sua... sua vagina, entendeu? Explica" (Patrícia, 60 anos).

Os resultados do exame informariam, também, sobre o estado da saúde sexual, conferindo o funcionamento interno do corpo, que seria "visto por dentro":

"Você não vê. Você tá vendo aqui seu cabelo, seu dedo, mas lá dentro você não tá vendo. Só eles os médicos e Deus é que vai dizer como é que tá você" (Amélia, 68 anos).

Para algumas informantes, o Papanicolaou permite detectar infecções e doenças no útero, enquanto, para outras, é realizado para previnir o câncer nesse órgão. Informantes na faixa etária entre 36 e 55 anos referem que o exame tem como função a prevenção do câncer cervical.

Além das variadas funções atribuídas ao Papanicolaou, a sua alta valorização é percebida nas falas de todas as entrevistadas, como exemplificado embaixo:

“... o preventivo sempre foi uma coisa do primeiro... é primeiro mundo, de muitos anos e vai ser sempre. Agora não vai deixar de fazer. E tem que fazer mesmo, né? Não tem como. Enquanto existir mulher, tem preventivo. (...) Tem mulher, tem preventivo" (Ivonne, 42 anos).

O Papanicolaou é uma prática associada com o desenvolvimento feminino, como ilustra nossa entrevistada mais nova, Rita, que já o havia realizado antes de iniciar a atividade sexual. Ela estabelece uma marcada diferença entre aquele exame e o próximo: o exame que ela fez quando era "uma menina" ainda virgem foi "mais rápido, mais simples"; entretanto, aquele que realizará em breve, por ter se tornado "mulher", "esse já é um completo". O primeiro Papanicolaou "normal" parece ser um momento marcante no processo pelo qual "a gente vai entrando no corpo de mulher".

Muitas entrevistadas referem, ainda, usar anticoncepcionais para evitar a gravidez, para controlar a menstruação e para amenizar mal-estares diversos. Elas relatam que realizam outros exames além do Papanicolaou, porém desconhecem a função deles. Várias afirmam ter realizado intervenções como ligaduras tubárias, curetagens, raspagens do útero, cauterizações e histerectomias. Assim, como o Papanicolaou é um dentre vários procedimentos médicos que fazem parte do que é "ser mulher", os significados e práticas associados ao exame requerem a sua contextualização no processo de medicalização do corpo feminino, orientada para a naturalização e normalização dos comportamentos sexuais e reprodutivos das mulheres 22 .

A junção mulher-preventivo foi analisada por Bush 23, que sinaliza que o discurso médico não seria apenas uma forma de controle do corpo feminino, mas uma base para a construção da feminilidade. Feminilidade que não seria produzida apenas em forma discursiva, mas também em forma performativa mediante práticas reiteradas 14,23 . A medicalização é caracterizada, na literatura feminista, tanto como uma fonte de opressão, quanto como uma contribuição para a liberação das mulheres 24 . Enquanto o rastreamento e outras práticas médicas representam uma possibilidade das mulheres ganharem controle sobre seus corpos, as noções difusas sobre a finalidade do Papanicolaou e de outras intervenções biomédicas fazem com que o balanço entre autonomia e sujeição resulte particularmente problemático 23,24 . 
De sujeiras e faxinas: câncer do colo uterino e corpo feminino

Apesar de todas as entrevistadas afirmarem que realizam o Papanicolaou, elas parecem ter mais consciência sobre a existência do câncer do colo uterino do que informação biomédica sobre ele. Elas imaginam que se trata de uma doença grave "que come a pessoa por dentro", refletindo a vigência das representações do câncer em geral 25. Algumas informantes a associam com caroços ou feridas que, caso não sejam tratados, levariam à enfermidade. Outras participantes afirmam que se trata do "problema mais importante para as mulheres", associando-o com a promiscuidade e o "mau uso" do corpo, evidenciando um forte atrelamento entre sexualidade, gênero e valores morais.

Lupton 24 afirma que as experiências corporais das mulheres não podem ser separadas dos discursos e das práticas que as constituem, salientando a influência médica. As concepções sobre o corpo feminino, fortemente influenciadas pelo discurso médico articulado ao gênero, privilegiam sua dimensão reprodutiva, o que se verifica na associação do útero com a identidade feminina 24 e especialmente com a função materna. A esse respeito, duas entrevistadas que realizaram histerectomias relataram que a retirada do útero não teve repercussões negativas porque elas já haviam ultrapassado a fase reprodutiva.

Algumas informantes referem que a doença atinge as "partes da gente", caracterizadas como "frágeis" e "sensiveis", coerentemente com a concepção sobre o corpo feminino em geral, de vulnerabilidade aparentemente constitutiva 24 . Essa concepção incidiria na distinção existente entre as práticas de cuidado de mulheres e homens. Segundo todas as entrevistadas, as mulheres zelam mais por sua saúde do que os homens, sobretudo por meio de ações preventivas ligadas à saúde ginecológica; eles, por sua vez, apenas procurariam atendimento diante de mal-estares inadiáveis.

Grande parte das estratégias populacionais de prevenção foca-se no corpo da mulher, enfatizando a sua função de mãe e cuidadora 23 . Nesse sentido, Lupton 24 destaca o papel da ginecologia na legitimação da concepção de que a sexualidade e a reprodução seriam esferas próprias das mulheres. Por sua vez, Moore 26 acrescenta que a "natureza de gênero" da promoção da saúde contribui para a vigilância de si, voltada ao controle da saúde sexual e reprodutiva feminina.

Com relação à prevenção do câncer do colo uterino, algumas mulheres mencionam a necessidade de realizar exames e controles de rotina, enquanto outras aludem especificamente ao $\mathrm{Pa}$ panicolaou. Outra forma de prevenção referida por algumas entrevistadas sugere significados outorgados ao corpo feminino. Associando a doença com a falta de higiene, Eva afirma que "após o ato sexual, é obrigação da mulher fazer o seu asseio, o asseio do seu corpo". A utilização de sabonetes íntimos e cremes vaginais sem prescrição médica é uma prática caracterizada como habitual pelas participantes. Coerentemente com a valorização da higiene íntima, a consulta ginecológica e o Papanicolaou também são significados nesses termos:

"Preventivo também deu tudo limpo; (...) esse último que eu fiz graças a Deus tava tudo limpo, tudo rosa..." (Janine, 28 anos).

"Eu gosto de sempre tá limpa. Médico me acompanhando, me dizendo o que eu tenho, o que eu não tenho. (...) ... eu não ando em médico toda hora... Mas quando eu tiro pra ir pro médico, você já viu a faxina que eu faço! (...) Eu gosto, eu gosto de fazer minha faxina geral" (Ivonne, 42 anos).

\section{Práticas preventivas e organização}

dos serviços

Em relação às pessoas que influíram na realização do Papanicolaou, várias entrevistadas, especialmente as jovens, mencionaram familiares ou amigas com quem tiveram as primeiras conversas sobre sexualidade, que as incentivaram para fazer o exame. $\mathrm{O}$ entorno feminino tem grande influência na construção social do conhecimento sobre cuidado à saúde sexual, conferindo às mulheres um papel de "educadoras mais bemsucedidas" 9 do que os médicos para incentivar a realização do Papanicolaou 21,27. Howson 28 afirma que o senso de obrigação para com outras mulheres significativas confere à adesão ao rastreamento um caráter relacional, conforme verificado no presente estudo.

As outras figuras de referência destacadas pelas entrevistadas são os médicos. A maioria fez o primeiro Papanicolaou em consultas de rotina depois do início da atividade sexual. Entre as mulheres mais velhas, o primeiro exame foi realizado no seguimento da gravidez, depois da maternidade ou por sugestão médica em consultas realizadas por queixas diversas. Uma vez que o rastreamento oportunístico do câncer do colo uterino baseia-se no oferecimento do Papanicolaou a mulheres em idade reprodutiva 5,10,23,29, as próprias mulheres o associam com essa fase vital 24 . No entanto, as entrevistadas entre 55 e 68 anos afirmam que continuam fazendo o exame.

No que diz respeito à periodicidade adequada para a realização do Papanicolaou, a maior parte das informantes afirma que ela é anual e 
declara fazer o exame com essa frequência como parte do check-up geral:

"Já fiz, esse ano mesmo já fiz preventivo, fiz mamografia, tá tudo aí. (...) Já fiz ultrassom da mama, e já fiz ultrassom também vaginal. Fiz tudo, né? Exame de sangue, fezes, faço tudo. (...)"(Grace, 66 anos).

Ao ser perguntada por que faz o preventivo, a mesma entrevistada afirma:

"Porque eu já acostumei. (...) Então todo ano eu procuro fazer. (...) E aí eu... Já fico tranquila. Porque sei que tá tudo bem" (Grace, 66 anos).

Outra participante declarou ainda fazê-lo a cada seis meses. Considerando as diretrizes locais do rastreamento do câncer do colo uterino, que sugerem que o exame seja realizado a cada três anos depois de dois resultados anuais normais 7, os dados obtidos remetem-nos novamente ao fenômeno da medicalização do corpo feminino. Entretanto, quando perguntada sobre a última vez em que havia realizado o Papanicolaou, uma entrevistada se deu conta do tempo transcorrido, pois estava ainda grávida de seu filho, há seis anos:

“... Eu fiz preventivo... olhe... gente, eu não vou mentir, não. Eu fiz preventivo quando eu tava grávida do meu filho. (...) Aaahhh... Tem um tempinho... [ri] Brincadeira, é... [ri] Mas eu sempre fazia, né? (...) Eu ia, fazia, o médico me dizia 'não tem nada'. (...) O tempo vai passando, você vai... Eu não sinto nada, mesmo. (...) Eu nem nunca fiquei esse tempo todo sem fazer. Isso aí meu agora foi um relaxamento. Porque eu... eu nem nunca fiquei... Da data que eu comecei fazer, eu, todo ano aqui, $\hat{o}$, fazendo preventivo. Todo ano fazendo meu preventivo" (Ivonne, 42 anos).

Pode-se apreciar a tensão existente entre a importância de realizar o exame com a periodicidade considerada certa e a concepção de que apenas seria necessário fazê-lo diante de queixas. Ilustrando a percepção da saúde como ausência de sintomas, Ivonne justifica o tempo transcorrido desde o último Papanicolaou afirmando que ela não percebeu alterações na sua urina. A não realização do exame até a apresentação de sintomas foi encontrada em outros estudos 12,29,30, todavia, em decorrência da significação do Papanicolaou como uma forma de cuidado da saúde sexual em geral, a maior parte das participantes desta pesquisa afirmou realizá-lo independentemente de moléstias. Algumas entrevistadas que possuíam informação biomédica sobre o câncer do colo uterino referiram ainda que os sintomas só são percebidos no estádio avançado da doença, salientando a importância do Papanicolaou para detectá-la oportunamente.

Algumas informantes referiram que outras mulheres do bairro não fazem o exame por di- ficuldades de acesso aos serviços de saúde. As barreiras de acessibilidade associadas à organização dos serviços 11,12,29 seriam condicionantes que, fugindo ao controle das mulheres, as "desculpariam” pela não realização do exame. Contudo, as entrevistadas que recorrem ao sistema público de saúde explicam com clareza o motivo. Como diz Luísa, de 58 anos, “quem não tem dinheiro faz pelo SUS”. Para tanto, deve-se chegar cedo às unidades de saúde e esperar em longas filas para tentar conseguir as escassas vagas disponíveis. Algumas mulheres combinam com outras para irem acompanhadas, diante do risco que implica sair sozinhas no bairro pela madrugada. Em face deste problema, é valorizado o papel dos agentes comunitários de saúde, que agendam o exame nas visitas domiciliares. Ainda assim, na data marcada, são frequentes as longas esperas, e o recebimento do resultado também implica tempo excessivo. Devendo-se agendar outra consulta para a leitura do resultado, esta também demora.

Sendo assim, por causa dessas dificuldades, algumas mulheres recorrem ao setor privado, enquanto outras combinam prestações de serviços dos diferentes setores. Elas realizam o Papanicolaou em postos de saúde e recorrem a médicos particulares ou, dispondo de acompanhamento ginecológico no âmbito público, fazem o exame em clínicas privadas. Para dimensionar o impacto dessa prática na economia familiar, cabe salientar que os grupos domésticos das entrevistadas têm rendas mensais inferiores a três salários mínimos e que frequentemente outras integrantes da família também realizam o exame. Como afirma Janine:

"Todo mundo ou conta com particular, essas clínicas que o preço são mais populares, ou... SUS. Se conseguir marcar pelo SUS, SUS. Só que é assim, difícil. (...) Eu faço com um ginecologista, que eu pago, também não tenho plano de saúde. (...) ... não é todo mundo que tem como tá pagando 80, 100 reais em uma consulta (...). Você acha hoje um preventivo de 35, 40 reais, mais a consulta, porque não adianta fazer só o preventivo, ter o resultado em mão e não saber ler o resultado. (...) Não é muuuuito dinheiro, mas também não é tão pouco. Oitenta reais vai fazer muita falta. Já são dois bujões de gás, sabe? O problema é esse" (Janine, 28 anos).

Segundo Mckie 31, o principal benefício do rastreamento do câncer do colo uterino para as mulheres é a tranquilidade de consciência, o que permite compreender não apenas a sua valorização, mas também a sua realização frequente e independente de queixas. 
Mulheres em risco, mulheres de risco: sexualidade e discurso moral da prevenção

A influência dos parceiros ocupa um lugar de destaque na literatura sobre rastreamento de câncer do colo uterino, podendo dificultar 9,10,21,29 ou propiciar $11,21,29$ a realização do Papanicolaou pelas mulheres. Este estudo encontrou que o apoio dos companheiros contribui para a realização do exame, porém outro aspecto relacionado apresentou-se de modo recorrente:

“... eu converso, ele sabe que eu vou fazer o preventivo, quando eu chego mostro o resultado: 'Olha, pai. A médica diz que está tudo OK, tá tudo limpinho. Ou você não me trai, ou então tá tudo certo"' (Janine, 28 anos).

A associação entre Papanicolaou e infidelidade faz com que algumas mulheres realizem o exame como forma de conferir a fidelidade dos parceiros 21,30 e, diante de um resultado anormal, experimentem a sensação de terem sido traídas 32 .

Nos discursos das participantes, encontrou-se uma diferenciação entre três tipos de companheiros. De um lado, estaria o parceiro "fixo" e "de confiança": aquele com quem se partilha um casamento duradouro, mas também aquele que, caso fosse "dar um pulinho fora", teria consciência da necessidade de cuidar de si e da sua companheira. O "culpado" seria infiel e promíscuo; indiferente ao cuidado de si e dos outros, transmitiria DSTs à sua companheira. Entre essas duas categorias, encontra-se o parceiro "suspeito", que seria o mais comum, já que nenhum homem é "santinho" e nunca se sabe o que ele faz "fora de casa". Evidencia-se que a infidelidade é associada à "natureza masculina", cuja intensidade e liberdade sexual fazem parte da construção do gênero brasileira 33

Uma vez que a sexualidade está atravessada por padrões morais e de gênero, as mulheres podem priorizar a relação com seus parceiros, com consequências negativas para a prevenção de doenças sexualmente transmissíveis 34 . Essa questão deve ser considerada em face do caráter sexualmente transmissível do HPV. Muitas entrevistadas estão cientes de que, por terem parceiros, elas ficam mais expostas ao câncer do colo do útero em decorrência da "natural" tendência masculina à infidelidade. Entretanto, quando consultadas sobre se alguma vez haviam se sentido em risco de adoecer por câncer do colo do útero, várias delas responderam de forma negativa, utilizando critérios vinculados à sexualidade para avaliar a susceptibilidade diante da doença. As mulheres com parceiro fixo e as que praticam uma religião que valoriza a fidelidade conjugal consideram que não vivem de forma "arrisca- da". Por sua vez, algumas participantes de idade avançada ou sem parceiro justificam a escassa possibilidade de contrair câncer do colo do útero em virtude da inatividade sexual, evidenciando uma percepção do risco associada à atividade sexual e uma concepção do contágio característica das infecções agudas 21 .

Como contrapartida, algumas entrevistadas afirmam que, mesmo realizando o Papanicolaou, todas as mulheres estão "na linha de risco". A prevenção tornar-se-ia relativa diante de uma doença caracterizada pelo acaso e pela fatalidade, refletindo as significações do câncer em geral 25. Porém, elas salientam a importância do exame para que, caso adoeçam, isso não se deva à própria "displicência". Evidenciando o peso do discurso da prevenção e da responsabilidade individual pelo cuidado da saúde 28 , o Papanicolaou não seria uma garantia certa contra a doença, mas uma prova da responsabilidade das mulheres que o realizam. O discurso sobre o rastreamento confere ao exame um caráter moral, que associa a sua realização com a normalidade e a correção femininas, desaprovando quem não cumpre com aquela sorte de dever feminino 23,28 .

Em face da valorização desta prática, as informantes afirmam que as mulheres que "não ligam" têm maior chance de contrair a enfermidade. Estas são aquelas que não visitam regularmente o ginecologista e as que não fizeram um acompanhamento médico adequado da gravidez, desconsiderando que a adoção dessas práticas está condicionada por fatores culturais e estruturais desigualmente distribuídos. Também as mulheres com vários parceiros, as usuárias de drogas e as que realizam abortos são indicadas como mais susceptíveis de contrair a enfermidade.

A pouca idade não seria um fator de risco em si próprio, mas estaria associada ao estilo de vida das mulheres jovens, caracterizado pela falta de responsabilidade e por uma sexualidade considerada precoce e arriscada. A entrevistada mais nova diferencia as mulheres jovens de "dentro de casa" daquelas que levam vidas arriscadas " $n a$ rua", refletindo a tradicional associação entre feminilidade e espaço doméstico.

A relação entre masculinidade e infidelidade faria com que as mulheres com parceiros pouco confiáveis, "que vão se perdendo com mulheres das ruas", tenham mais possibilidades de adoecer. Contudo, chama a atenção o fato de que não seriam os homens os principais responsáveis por colocar as suas parceiras em risco. Em última instância, por trás de todo homem há uma mulher:

"Porque os homens hoje em dia a gente não deve confiar neles. (...) A gente tá crente que... só tem a ele dentro de casa, mas não. Entendeu? Você 
sabe que não é porque... é desfazendo das mulheres não... que elas hoje em dia... tão ali, tão se jogando mesmo... E diz mesmo, 'Eu gosto mais de homem casado que homem solteiro'. Entendeu? Então a gente tem que se prevenir" (Patrícia, 60 anos).

Em suma, mulheres com comportamentos reprovados seriam as candidatas por excelência ao câncer do colo do útero. Braun \& Gavey 37 assinalam a vigência de um discurso dicotômico focado nas DSTs que, mediante a distinção entre mulheres sexualmente "boas" e "más", contribui para o julgamento e controle da sexualidade feminina. Enquanto, entre os homens, as DSTs seriam o produto "natural" do seu comportamento sexual, entre as mulheres, são experimentadas como (merecido) castigo por condutas consideradas impróprias. Diante da restrita possibilidade de escolha entre as categorias "promíscua-vulnerável” ou "não promíscua-segura", e afastando-se dessas "outras" moralmente questionáveis, as mulheres que se veem como "boas", segundo padrões de gênero e valores morais dominantes, excluem-se do risco do câncer do colo do útero, que passa a não ser percebido como um problema potencial.

\section{Considerações finais}

Os dados produzidos apontam uma forte valorização do Papanicolaou pelas entrevistadas, que lhe conferem diversas funções e graus de especificidade. Considerado como uma prática de cuidado da saúde sexual em geral, ele é realizado como parte de exames de rotina.

Enquanto são apontados diversos obstáculos para o rastreamento do câncer do colo do útero na rede pública de saúde, salienta-se o impacto que representa, na economia doméstica das participantes, a realização do exame no setor privado. Todavia, apesar das dificuldades relatadas, as informantes salientam que nunca desistiram de fazer o Papanicolaou, confirmando a associação deste com a feminilidade, a responsabilidade e a maturidade.

Além da disponibilidade e da qualidade dos serviços, determinados discursos e relações sociais interferem na forma como as mulheres outorgam significado e agem em face do câncer do colo do útero. $\mathrm{O}$ apoio dos parceiros favorece a realização do Papanicolaou, e o entorno feminino tem especial influência no cuidado da saúde sexual, conferindo ao rastreamento um forte caráter relacional. Valores morais e afetivos atravessam a sexualidade, interferindo na percepção de risco e na adoção de práticas preventivas. A naturalização da infidelidade masculina faz com que as mulheres com parceiros sejam indicadas como aquelas com maiores possibilidades de contrair a doença, sendo essa susceptibilidade atenuada em casos de relacionamentos duradouros com "parceiros confiáveis". Menores probabilidades de desenvolver câncer do colo do útero também são associadas à falta de atividade sexual e à finalização da etapa reprodutiva.

Apesar disso, a realização do Papanicolaou não as eximiria da possibilidade de contraírem a enfermidade. As representações do câncer em geral relativizam a possibilidade de prevenção e cura desse tumor; entretanto, a prática do exame evidenciaria a maturidade e a responsabilidade pessoal pelo cuidado da saúde. A concepção individualizante da prevenção propicia a distinção entre as mulheres que não fazem o Papanicolaou por dificuldades estruturais e aquelas cujas práticas (sexuais e de cuidado) são consideradas moralmente incorretas. A maior susceptibilidade de adoecer decorreria, em suma, da falta de responsabilidade pelo cuidado de si, o que contribuiria para culpabilizar as mulheres por seu adoecimento com base em um discurso moral.

Assim, os resultados do Papanicolaou são interpretados em termos que transcendem o câncer do colo do útero. Eles informam sobre a saúde sexual em geral, a "limpeza" e a fidelidade conjugal, trazendo "tranquilidade" pelo cumprimento de uma obrigação associada à feminilidade. O exame, apesar de rotineiro, está longe de ser uma técnica neutra; pelo contrário, constitui uma prática inserida em um enquadramento moral de autorresponsabilidade e de obrigação para com outros/as.

Diante dos obstáculos e facilitadores encontrados, espera-se trazer elementos capazes de subsidiar dinâmicas de atenção em acordo com as necessidades das mulheres mais vulneráveis ao câncer do colo do útero, no que diz respeito aos horários de atendimento e aos tempos de espera. Também os achados sobre os discursos que relacionam o gênero e a sexualidade à doença podem colaborar com aquele propósito. A caracterização do câncer cervical como um importante problema feminino pode ser aprofundada por meio de estratégias comunicativas que forneçam informações relevantes e culturalmente pertinentes sobre a enfermidade (longo período de desenvolvimento, idade de risco e possibilidade de prevenção e cura) e sobre o Papanicolaou (especificidade em relação ao câncer do colo do útero). Sabendo-se que valores morais perpassam os significados e práticas associados à doença, dificultando a visualização desta como um risco potencial entre mulheres com parceiros fixos, de idade avançada ou sem atividade sexual, ações dirigidas a estes grupos são recomendadas. 
Ademais, considerando o caráter relacional do rastreamento, atividades de educação em saúde entre mulheres teriam impacto positivo.

Por fim, é fundamental considerar a tensão que a medicalização traz entre a vigilância de si e as possibilidades das mulheres ganharem controle sobre os seus corpos. O rastreamento do câncer do colo do útero, fortemente associado à feminilidade - longe de contribuir para a culpabilização daquelas que descumpririam os imperativos de cuidado e de sexualidade considerados corretos -, deve propiciar oportuni-

\section{Resumen}

El objetivo de este trabajo fue comprender los significados de las prácticas preventivas del cáncer de cuello de útero entre mujeres de barrios populares de Salvador, Bahía, Brasil. Se trata de un estudio cualitativo, basado en el análisis de contenido de entrevistas semiestructuradas con 15 mujeres entre 24 y 68 años. Los resultados evidencian una alta valorización del Papanicolaou, que es realizado como parte de exámenes de rutina sin estar basado, no obstante, en el conocimiento biomédico sobre sus funciones. Más allá de la accesibilidad $y$ de la calidad de los servicios de salud, otros factores influyen en la forma en que estas mujeres consideran la prevención del cáncer de cuello de útero. Los valores morales asociados a la sexualidad y al género influyen en la percepción de riesgo, en la adopción de prácticas preventivas y en la interpretación de los resultados de la citología cervical. La realización continuada del Papanicolaou forma parte de la construcción de la feminidad, que está asociada con la madurez y la responsabilidad personal por el cuidado de uno mismo en un contexto de medicalización del cuerpo femenino.

Prevención de Cáncer de Cuello Uterino; Identidad de Género; Sexualidad dades para as mulheres ganharem autonomia sobre os seus corpos e saúde. Assim, a oferta do Papanicolaou deve visar a garantir direitos, e não criar obrigações e sanções, em relação ao "ser mulher". Em suma, a prevenção do câncer cervical deveria atentar para ações cujo propósito seja propiciar a passagem da mera adesão para uma "participação informada", por parte das mulheres, no rastreamento, sustentada não apenas no fornecimento de informações, mas, sobretudo, no reconhecimento dos seus valores e práticas.

\section{Colaboradores}

A. M. Rico realizou a pesquisa bibliográfica, o trabalho de campo, a análise dos dados e a redação do artigo. J. A. B. Iriart orientou a pesquisa e colaborou na análise dos dados e na redação do artigo.

\section{Agradecimentos}

Às instituições em que se realizou o trabalho de campo e às mulheres que participaram do estudo. À Capes e ao CNPq, pela bolsa de estudos para a primeira autora. 


\section{Referências}

1. International Agency for Research on Cancer; World Health Organization. IARC Handbooks of Cancer Prevention. Cervix cancer screening. v. 10. Lyon: IARC Press; 2005.

2 Ferlay J, Shin HR, Bray F, Forman D, Mathers C, Parkin DM. Globocan 2008: cancer incidence and mortality worldwide. v.1.2. (IARC CancerBase, 10) http://globocan.iarc.fr (acessado em Set/2011).

3. Instituto Nacional de Câncer. Estimativa 2012. Incidência do câncer no Brasil. http://www1.inca. gov.br/estimativa/2012/estimativa20122111.pdf (acessado em Fev/2012).

4. Instituto Nacional de Câncer. Atlas da mortalidade por câncer. http://mortalidade.inca.gov.br/Morta lidade/ (acessado em Fev/2012).

5. Alvarez S. Aspectos socio-culturales de la sexualidad como factores obstaculizantes de la prevención secundaria del cáncer cérvico uterino. Cad Saúde Pública 1998; 14 Suppl 1:S33-40.

6. Coordenação Geral de Apoio à Gestão Descentralizada, Departamento de Apoio à Descentralização, Secretaria Executiva, Ministério da Saúde. Diretrizes operacionais dos Pactos pela vida, em defesa do SUS e de gestão. Brasília: Ministério da Saúde; 2006.

7. Instituto Nacional de Câncer. Programa Nacional de Controle do Câncer do Colo do Útero. Diretrizes do rastreamento. http://www2.inca.gov.br/wps/ wcm/connect/acoes_programas/site/home/no brasil/programa_nacional_controle_cancer_colo_ utero/deteccao_precoce (acessado em Fev/2012).

8. Schmidt MI, Duncan BB, Azevedo e Silva G, Menezes AM, Monteiro CA, Barreto SM, et al. Chronic non-communicable diseases in Brazil: burden and current challenges. Lancet 2011; 377:1949-61.

9. Wood K, Jewkes R, Abrahams N. Cleaning the womb: constructions of cervical screening and womb cancer among rural black women in South Africa. Soc Sci Med 1997; 45:283-94.

10. Agurto I, Bishop A, Sanchez G, Betancourt Z, Robles S. Perceived barriers and benefits to cervical cancer screening in Latin America. Prev Med 2004; 39:91-8.

11. Bingham A, Bishop A, Coffey P, Winkler J, Bradley J, Dzuba I, et al. Factors affecting utilization of cervical cancer prevention services in low-resource settings. Salud Pública Méx 2003; 45:408-16.

12. Amorim VMSL, Barros MBA, César CLG, Carandina L, Goldbaum M. Fatores associados à não realização do exame de Papanicolaou: um estudo de base populacional no Município de Campinas, São Paulo, Brasil. Cad Saúde Pública 2006; 22:2329-38.

13. Scott J. Gênero: uma categoria útil de análise histórica. Educação \& Realidade 1990; 16:5-22.

14. Butler J. Problemas de gênero. Feminismo e subversão da identidade. Rio de Janeiro: Editora Civilização Brasileira; 2003.

15. Conrad P. The medicalization of society: on the transformation of human conditions into treatable disorders. Baltimore: John Hopkins University Press; 2007.
16. Courtenay WH. Constructions of masculinity and their influence on men's well-being: a theory of gender and health. Soc Sci Med 2000; 50:1385-401.

17. Bardin L. Análise de conteúdo. Lisboa: Edições 70; 1977.

18. Uchoa E, Vidal JM. Antropologia médica: elementos conceituais e metodológicos para uma abordagem da saúde e da doença. Cad Saúde Pública 1994; 10:497-504.

19. Martin E. A mulher no corpo. Uma análise cultural da reprodução. Rio de Janeiro: Editora Garamond; 2006.

20. Minayo MC. Saúde-doença: uma concepção popular da etiologia. Cad Saúde Pública 1988; 4:363-81.

21. Wiesner-Ceballos C, Vejarano-Velandia M, Caicedo-Mera J, Tovar-Murillo S, Cendales-Duarte R. La citología de cuello uterino en Soacha, Colombia: representaciones sociales, barreras y motivaciones. Rev Salud Pública 2006; 8:185-96.

22. Costa T, Stotz E, Grynszpan D, Souza MC. Naturalização e medicalização do corpo feminino: o controle social por meio da reprodução. Interface Comun Saúde Educ 2006; 10:363-80.

23. Bush J. It's just a part of being woman: cervical screening, the body and feminity. Soc Sci Med 2000; 50:429-44.

24. Lupton D. Medicine as culture: illness, disease and the body in western societies. London: Sage; 1994.

25. Sontag S. La enfermedad y sus metáforas y el Sida y sus metáforas. Buenos Aires: Taurus; 2005.

26. Moore SEH. Is the healthy body gendered? Toward a feminist critique of the new paradigm of health. Body \& Society 2010; 16:95-118.

27. Calvo A. Social construction of cervical cancer screening among women in Panama City, Panama [Doctoral Dissertation]. Florida: University of South Florida; 2005.

28. Howson A. Cervical screening, compliance and moral obligation. Soc Health Illn 1999; 21:401-25.

29. Brenna SMF, Hardy E, Zeferino LC, Namura I. Conhecimento, atitude e prática do exame de Papanicolaou em mulheres com câncer de colo uterino. Cad Saúde Pública 2001; 17:909-14.

30. Duavy LM, Batista FL, Jorge MS, Santos JB. A percepção da mulher sobre o exame preventivo do câncer cérvico-uterino: estudo de caso. Ciênc Saúde Coletiva 2007; 12:733-42.

31. Mckie L. The art of surveillance or reasonable prevention? The case of cervical screening. Soc Health Illn 1995; 17:441-57.

32. Blomberg K, Forss A, Ternestedt BM, Tishelman C. From "silent" to "heard": professional mediation, manipulation and women's experiences of their body after an abnormal Pap smear. Soc Sci Med 2009; 68:479-86.

33. Parker R. Corpos, prazeres e paixões. A cultura sexual no Brasil contemporâneo. São Paulo: Editora Best Seller; 1991. 
34. Heilborn ML, Gouveia P. "Marido é tudo igual": mulheres populares e sexualidade no contexto da AIDS. In: Barbosa R, Parker R, organizadores. Sexualidades pelo avesso: direitos, identidades e poder. Rio de Janeiro: Instituto de Medicina Social, Universidade do Estado do Rio de Janeiro/Editora 34. p. $175-98$.
35. Braun V, Gavey N. "Bad girls" and "good girls"? Sexuality and cervical cancer. Womens Stud Int Forum 1999; 22:203-13.

Recebido em 06/Out/2012

Versão final reapresentada em 25/Fev/2013

Aprovado em 26/Fev/2013 